\title{
Site-specific DNA Mapping of Protein Binding Orientation Using Azidophenacyl Bromide (APB)
}

\author{
Himasha M. Perera and Michael A. Trakselis*
}

Department of Chemistry and Biochemistry, Baylor University, Waco, Texas, 76798, USA

*For correspondence: michael trakselis@baylor.edu

\begin{abstract}
[Abstract] The orientation of a DNA-binding protein bound on DNA is determinative in directing the assembly of other associated proteins in the complex for enzymatic action. As an example, in a replisome, the orientation of the DNA helicase at the replication fork directs the assembly of the other associated replisome proteins. We have recently determined the orientation of Saccharalobus solfataricus (Sso) Minichromosome maintenance (MCM) helicase at a DNA fork utilizing a site-specific DNA cleavage and mapping assay. Here, we describe a detailed protocol for site-specific DNA footprinting using 4-azidophenacyl bromide (APB). This method provides a straightforward, biochemical method to reveal the DNA binding orientation of SsoMCM helicase and can be applied to other DNA binding proteins.
\end{abstract}

Keywords: MCM helicase, DNA replication, Site-specific footprinting, Orientation, DNA translocation, DNA mapping

[Background] DNA replication is the process in which the duplex genomic strands separate into two template strands, the leading and lagging strands. This function is executed by a ring-shaped hexameric helicase in all Domains of life. Like other ring-shaped hexameric helicases, MCM consists of two domains; an N-terminal domain (NTD) and a C-terminal domain (CTD). In theory, either of these domains could be oriented towards the replication fork during translocation and be consistent with the known 3'-5' translocation directionality. The MCM helicase loads onto DNA origins as a double hexamer with NTDs facing each other. The orientation of the helicase during translocation determines whether the two hexamers dissociate away from each other or bypass one another during active unwinding. Our recent paper shows that the Saccharolobus solfataricus (SsoMCM) unwinds DNA with NTD leading the way (Perera and Trakselis, 2019).

In order to directly determine the translocation orientation, we utilized a combination of site-specific DNA footprinting, single turnover unwinding, and translocation assays. Here, we provide detailed protocols of site-specific DNA footprinting assays with 4-azidophenacyl bromide (APB) to analyze the translocation orientation of SsoMCM (Pendergrast et al., 1992, Kassabov and Bartholomew, 2004, Nodelman et al., 2017).

APB is a heterobifunctional photoactivatable crosslinking agent. Its bromide functional group reacts by S-alkylation with reduced thiols (i.e., cysteines) to form stable thioether products (Figure 1). After binding of the functionalized protein to DNA and then exposure to UV light, a reactive singlet nitrene forms that can crosslink to either protein or DNA (in close proximity) through multiple insertion or addition mechanisms (Figure 1). The resulting crosslinked protein-DNA complex can be cleaved at the 
crosslinked nucleotide(s) under induced alkali/heat treatment. The lengths of the resulting DNA fragments can be used to determine the orientation distribution of the SsoMCM helicase on DNA. This is a straightforward biochemical method that reveals unique positions of SsoMCM helicases on DNA. It has an important advantage over traditional footprinting in that it can determine protein binding orientation on DNA instead of just binding site size.

Useful applications of this method can be employed at instances where the 3D structure of the protein is known or can be predicted, but the 3D structure of the protein-DNA complex is unknown (Pendergrast et al., 1992). It is especially useful in determining the orientation of proteins that translocate along DNA or for those that bind to specific DNA sequences. Alternatively, the orientation of DNA-binding proteins can also be determined by other biochemical methods that employ localized hydroxyl radical Fenton footprinting reactions utilizing 1-(p-Bromoacetamidobenzyl) ethylenediamine N,N,N (Fe-BABE), similarly (Owens et al., 1998).
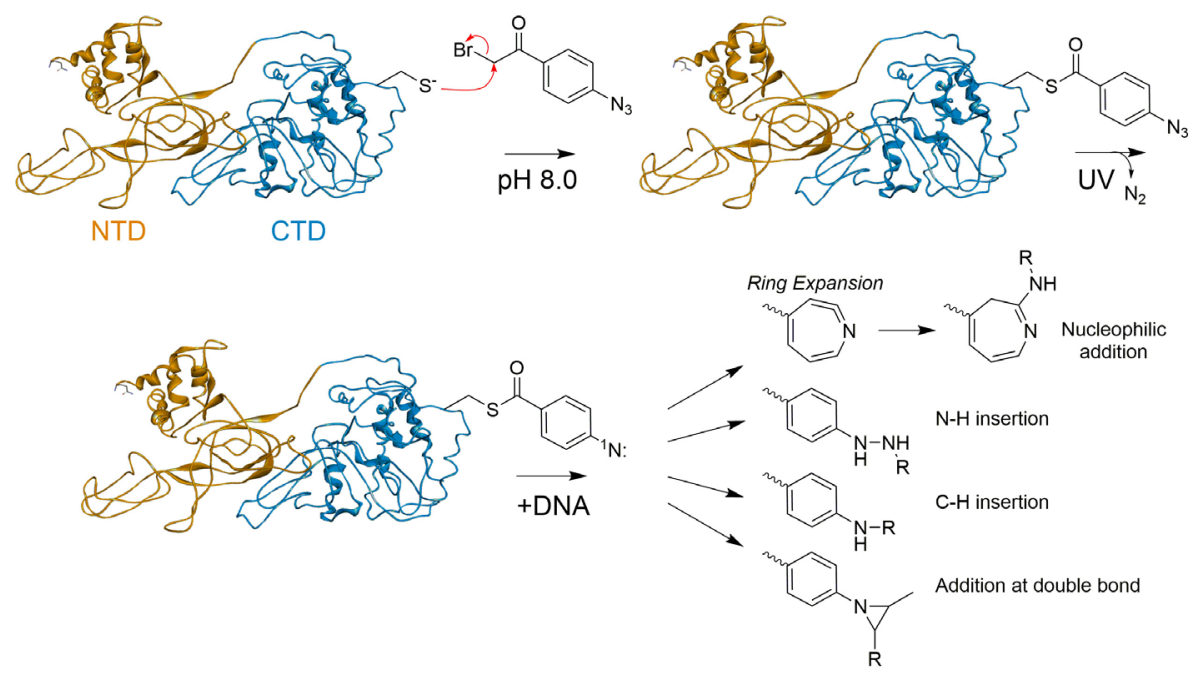

Figure 1. Conjugation of APB to free Cys on SsoMCM and UV induced crosslinking reaction mechanism to DNA

\section{Materials and Reagents}

1. Cover slips (Fisher Scientific, catalog number: 12-546)

2. Glass Petri dish (Corning, catalog number: 3160100)

3. Kimwipe (Kimberly-Clark, catalog number: 06-666)

4. p-Azidophenacyl bromide (APB) (Sigma-Aldrich, catalog number: $57018-46-9$, storage: $4{ }^{\circ} \mathrm{C}$ or (Fisher Scientific, catalog number: 50-520-767)

5. Dimethylformamide (DMF) (EMD Millipore Corporation, catalog number: DX1730-6)

6. Tris Base (Fisher Scientific, catalog number: 77-86-1)

7. Glacial acetic acid (Mallinckrodt Baker, Inc., catalog number: UN 2789)

8. Sodium chloride ( $\mathrm{NaCl}$ ) (Fisher Scientific, catalog number: S271-3)

9. Sodium hydroxide ( $\mathrm{NaOH}$ ) (Mallinckrodt Baker, Inc., catalog number: 7708-10) 
10. Hydrochloric acid ( $\mathrm{HCl})$ (Fisher Scientific, catalog number: A144-212)

11. Magnesium chloride $\left(\mathrm{MgCl}_{2}\right)$ (Spectrum Chemical, catalog number: $\left.\mathrm{M} 1035\right)$

12. Glycerol (Fisher Scientific, catalog number: BP-229-4)

13. Sodium acetate ( $\mathrm{NaOAc}$ ) (Fisher Scientific, catalog number: S210-500)

14. Potassium acetate (KOAc) (EM Science Industries, catalog number: $P X 1330-1$ )

15. Magnesium acetate (MgOAc) (Sigma-Aldrich, catalog number: M-0631)

16. Ammonium acetate ( $\mathrm{NH}_{4} \mathrm{OAc}$ ) (Mallinckrodt Baker, Inc., catalog number: 0596-01)

17. Bovine serum albumin (BSA) (Fisher Scientific, catalog number: BP1600-100)

18. Dithiotheritol (DTT) (Fisher Scientific, catalog number: BP172-5)

19. Ethylenediaminetetraacetic acid (EDTA) (Sigma-Aldrich, catalog number: E5134)

20. Sodium dodecyl sulfate (SDS) (Fisher Scientific, catalog number: 151-21-3)

21. Salmon sperm DNA (Invitrogen, catalog number: 15632-011, storage temperature: $-20^{\circ} \mathrm{C}$ )

22. Ethanol (Fisher Scientific, catalog number: A962-4)

23. Poly-L-lysine (Sigma-Aldrich, catalog number: P4832)

24. Orange $G$ dye (EMD Millipore Corporation, catalog number: 312-12)

25. SsoMCM protein

SsoMCM protein was purified as previously described (McGeoch et al., 2005; Graham et al., 2011). Any DNA binding protein with a suitable single cysteine residue can be utilized with this approach. It will help if that cysteine residue is solvent accessible from structural data. If a single cysteine is not available, then site-directed mutagenesis can be used to add a cysteine at the appropriate position to test.

26. Fluorescent (5' or $3^{\prime}$ ) labelled (Cy3 or Cy5) DNA (purchased from IDT (Coralville, IA) or SigmaAldrich (St. Louis, MO)) (Synthesis scale-0.025 $\mu$ mole, Purification: Desalt, Format: Dry). Note: PAGE purification of DNA can be performed depending on the purity of the DNA.

27. DNA Sequences for the 3'-long arm fork substrates

a. DNA $165-3\left(5^{\prime}\right.$ Су3 $)$

\section{5' 3'TCCCACCCAACCCGACCGGCATCTAGTCTGGTAGCGTGAGCGAACGGACC}

\section{b. DNA 171}

5' CTAACTGCGCCGGTCGGGTTGGGTGGGA

28. $1 x$ complex buffer (CB) (see Recipes)

29. Annealing buffer (see Recipes)

30. Post irradiation buffer (see Recipes)

31. Glycerol loading buffer (see Recipes)

32. $20 \%$ Native PAGE (see Recipes)

\section{Equipment}

1. Pipettes

2. $-80^{\circ} \mathrm{C}$ freezer 
3. Benchtop 3UV transilluminator (UVP, model: LMS-20E, catalog number: P/N 95-0220-01)

4. Typhoon FLA 9000 imager (GE Healthsciences)

5. PCR Instrument (BioRad laboratories (Hercules, CA)

6. Benchtop microcentrifuge (Eppendorf, model: 5424R)

7. Mini-PROTEAN Tetra Vertical Electrophoresis Cell for Mini Precast Gels (Bio-Rad Laboratories)

8. LightSafe micro centrifuge tubes (Sigma-Aldrich, catalog number: Z688312)

9. Dark room (Recommended)

\section{Software}

1. Image Quant (v.5.0) (GE Healthsciences, (Pittsburgh, PA))

\section{Procedure}

A. SsoMCM Protein labelling with APB

1. In the dark, dissolve APB in $100 \%$ DMF at a concentration of $40 \mathrm{mM}$. Notes:

a. Dark conditions can be provided by using LightSafe micro centrifuge tubes, covering Eppendorf tubes in foil or turning off the lights.

i. Use LightSafe micro centrifuge tubes when preparing APB solutions.

ii. Use clear micro centrifuge tubes covered in foil in subsequent reactions for easy visualization of a pellet and/or to achieve complete discarding of a supernatant.

b. When measuring $A P B$, quantities as small as $\sim 2 \mathrm{mg}$ can be measured under dark conditions.

c. Use freshly resuspended $A P B$ for each new experiment. Discard the unused APB.

2. Dilute the APB to $4 \mathrm{mM}$ in $20 \mathrm{mM}$ Tris $\mathrm{pH} 7.5,75 \mathrm{mM} \mathrm{NaCl}, 10 \%$ glycerol and $10 \%$ DMF.

3. Add the diluted APB to a sample of the protein ( $\sim 10 \mu \mathrm{M}$ monomer) containing a single reduced cysteine (in $20 \mathrm{mM}$ Tris [pH 7.5], $75 \mathrm{mM} \mathrm{NaCl}, 10 \%$ glycerol), to achieve a final concentration of $0.4 \mathrm{mM} \mathrm{APB}$ and $1 \%$ DMF.

Note: Cysteines must be reduced before conjugation with $A P B$, followed by gel filtration or dialysis to remove the reducing agent. Alternatively, tris(2-carboxyethyl)phosphine (TCEP) can be used without subsequent removal.

4. Proceed labelling for $2-3 \mathrm{~h}$ at room temperature.

B. Preparing silanized coverslips

1. Dilute poly-L-lysine solution with distilled water for 1:10.

2. Place the coverslips $(\sim 15)$ in a Petri dish.

3. Pour the solution ( $\sim 20 \mathrm{ml}$ ) on the coverslips (make sure the coverslips sink in).

4. Leave it in the solution for $15-30 \mathrm{~min}$.

5. Rinse the coverslips with water three times at Room Temperature (RT). 
6. Air dry the coverslips placing a kimwipe on top of the Petri dish (avoid touching the coverslips).

7. Coverslips can be prepared ahead of time and can be stored at RT for several weeks.

C. Preparing annealed fork DNA

1. Prepare stock solutions $(100 \mu \mathrm{M})$ of each complementary DNA strand in water (DNA 165-3 and DNA 171).

2. Mix the DNA in equal $1: 1(5 \mu \mathrm{M})$ concentration in water or annealing buffer.

Note: EDTA (chelates divalent metal ions) and salt in the annealing buffer facilitate duplex stability. But annealing DNA in water has also yielded in a complete duplex.

3. Heat at $95^{\circ} \mathrm{C}$ for $5 \mathrm{~min}$ and cool at a rate of $1{ }^{\circ} \mathrm{C} / \mathrm{min}$ to room temperature in a PCR instrument.

D. Preparing the crosslinked protein-DNA complex

1. Incubate APB labelled SsoMCM with fluorescent (Cy3) fork DNA (150 nM) for 10-20 min in 1x $\mathrm{CB}$ buffer in $50 \mu$ volumes (maintaining stochiometric $\sim 1: 1 \mathrm{MCM} 6$ :DNA ratio).

Note: Fluorescently labelled DNA is used here, but ${ }^{32} P$ labelled DNA can also be utilized.

2. Transfer the sample into silanized coverslips. Pipette $50 \mu \mathrm{l}$ of the sample into the middle of the coverslip.

3. UV irradiate for $15 \mathrm{~s}$ (302 $\mathrm{nm}$ UV-B).

4. Transfer the sample into an Eppendorf tube.

5. Add $150 \mu \mathrm{l}$ of post irradiation buffer.

6. Vortex at RT and place at $70^{\circ} \mathrm{C}$ for $20 \mathrm{~min}$.

E. Separate the crosslinked protein-DNA complex

1. Next, add $1 \mu \mathrm{l}$ of $10 \mathrm{mg} / \mathrm{ml}$ Salmon sperm DNA, $30 \mu \mathrm{l}$ of $3.0 \mathrm{M} \mathrm{NaOAc}, 750 \mu \mathrm{l}$ of ice cold $100 \%$ ethanol, vortex, and leave on ice for $1-2 \mathrm{~h}$ at $-80^{\circ} \mathrm{C}$.

2. Spin down the samples in microfuge at $4{ }^{\circ} \mathrm{C}, 16,000 \times \mathrm{g}$ for $30 \mathrm{~min}$.

3. Discard the supernatant and wash the pellet twice with ice cold $70 \%$ ethanol.

Note: In most of the steps, the DNA pellets are invisible. Discard the supernatant completely and resuspend in the subsequent buffer.

4. Spin down the samples in microfuge at $4{ }^{\circ} \mathrm{C}, 16,000 \times \mathrm{g}$ for $30 \mathrm{~min}$.

5. Remove ethanol and air dry the pellets by inverting on bench for $1 \mathrm{~h}$.

6. Resuspend the pellet in $100 \mu \mathrm{l}: 20 \mathrm{mM} \mathrm{NH}_{4} \mathrm{OAc}, 2 \%$ SDS, $0.1 \mathrm{mM}$ EDTA pH 8.0 by vortexing.

7. Spin down the samples in microfuge at room temperature, $16,000 \times \mathrm{g}$ for $10 \mathrm{~min}$.

8. Transfer the supernatant into fresh tubes and place in heat block at $90{ }^{\circ} \mathrm{C}$ for $2 \mathrm{~min}$.

9. Then, add $1 \mu \mathrm{l}$ of $2 \mathrm{M} \mathrm{NaOH}$, vortex briefly, and incubate at $90^{\circ} \mathrm{C}$ for $20 \mathrm{~min}$.

10. After incubation, pulse spin the samples, add $101 \mu \mathrm{l} 20 \mathrm{mM}$ Tris- $\mathrm{HCl} \mathrm{pH} 8.0,1 \mu \mathrm{l}$ of $2 \mathrm{M} \mathrm{HCl}$, $1 \mu \mathrm{l}$ of $2 \mathrm{M} \mathrm{MgCl}_{2}, 480 \mu \mathrm{l} 100 \%$ ethanol, vortex, and place at $-80^{\circ} \mathrm{C}$ for $1-2 \mathrm{~h}$.

11. Pellet the samples in microfuge at $4{ }^{\circ} \mathrm{C}$ at $16,000 \times \mathrm{g}$ for $30 \mathrm{~min}$, wash two times with ice cold $70 \%$ ethanol, and air dry on bench for $1 \mathrm{~h}$. 
12. Resuspend the DNA pellet with $5 \mu \mathrm{l}$ of $40 \%$ glycerol loading buffer containing Orange $\mathrm{G}$ dye for gel loading.

13. Electrophorese the samples on a $20 \%$ TBE-PAGE (native PAGE) in 1x TBE (Tris base, Boric acid, EDTA) at constant $30 \mathrm{~mA}$ for $45 \mathrm{~min}$, and visualize on a Typhoon FLA 9000 imager (GE Healthsciences).

\section{Data analysis}

1. Quantifying the density of DNA bands on the gel (Figure 2A) is performed by ImageQuant software.

2. Calculation of the footprinting percentages (Figure $2 B$ ) is performed by quantifying the relative density (minus background) for the labelled strand, divided at the midpoint on the ssDNA arm according to the following equation:

$$
F=\frac{(X @ \text { duplex }- \text { Control })}{((N @ \text { duplex }- \text { Control })+(C @ \text { duplex }- \text { Control }))}, X=C, N
$$

A)

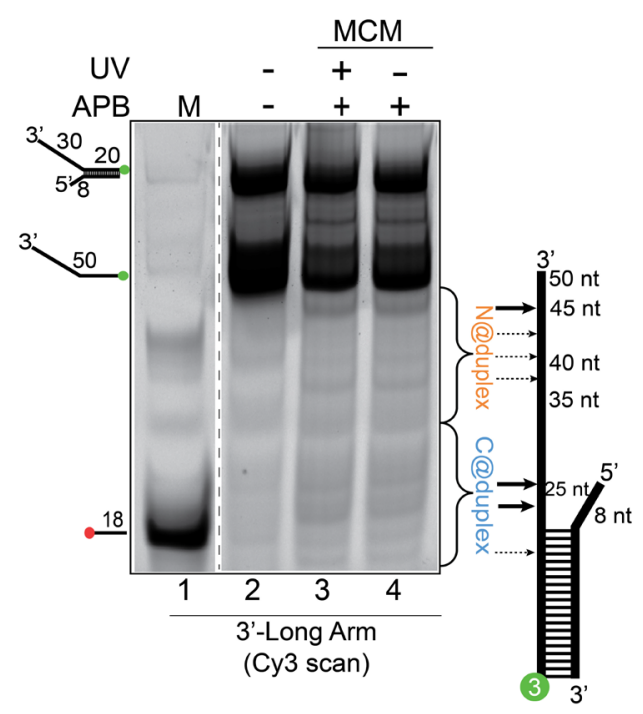

B)

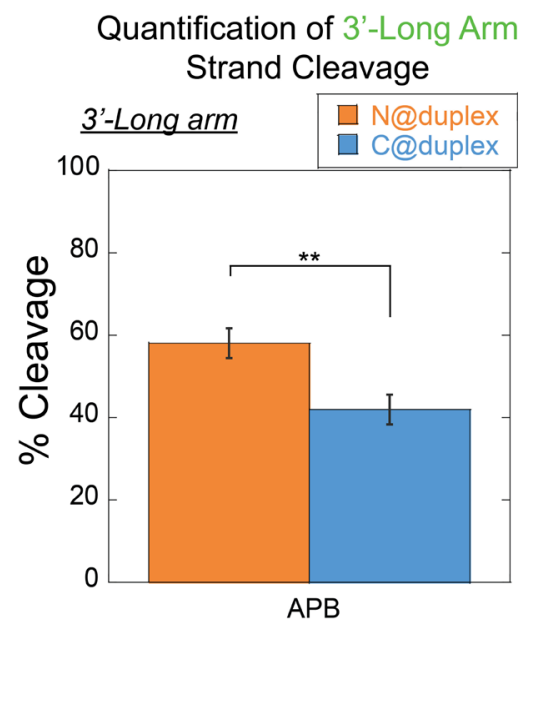

Figure 2. SsoMCM orientation mapping onto 3 '-(DNA171/165-3) long arm fork DNA

substrate. A. APB orientation mapping of the $3^{\prime}$-encircled strand labelled at the $5^{\prime}$ duplex end with Cy3 on a 3'-long arm fork DNA substrate with a 20 base duplex. SsoMCM was labelled at C682 with APB specifically. B. Quantification of the relative amount of DNA cleavage for bases 20-35 or 36-50 from the 5'-end indicate the relative orientation for placing the $N @$ duplex (orange) or $\mathrm{C} @$ duplex (blue), respectively closer to the duplex junction. DNA markers (M) indicate 18, 50 bases and fork DNA. Error bars represent standard error from 3-5 independent experiments. $P$-value is defined as ${ }^{* *}<0.01$. 
3. A standard two-tailed equal variance Student's $t$-test is used to determine significant differences of C@duplex versus N@duplex. P-values are reported for each experimental condition. Detailed explanation on data analysis can be found in the original research paper Figures $1 \mathrm{C}$ and 1F, 2B and 2D, 3C and 2E (Perera and Trakselis, 2019).

\section{$\underline{\text { Notes }}$}

1. Control experiments are performed with APB-MCM-DNA in the absence of UV light and/or with DNA alone in the absence of UV and APB. After activation by UV light, the crosslinking of APB to DNA bases is generally non-specific, yet we detected significant crosslinking and subsequent ssDNA cleavage even in the absence of direct UV light.

2. Similarly, 1-(p-Bromoacetamidobenzyl) ethylenediamine N,N,N (Fe-BABE) (Dojindo, Rockville, Maryland) can also be used in orientation mapping studies (Figure 1B and 1E in Perera and Trakselis, 2019). FeBABE utilizes a localized hydroxyl radical Fenton footprinting reaction. Rapid reactions generating high yields, mild protein conjugation and cleavage reaction conditions, non-sequence specific DNA cleavage are some advantages of utilizing FeBABE (Ishihama, 2000).

\section{Recipes}

1. $1 \times C B$ (complex buffer)

$20 \mathrm{mM}$ TrisOAc

$25 \mathrm{mM} \mathrm{KOAc}$

$10 \mathrm{mM} \mathrm{MgOAc}$

$0.1 \mathrm{mg} / \mathrm{ml} \mathrm{BSA}$

$1 \mathrm{mM} \mathrm{DTT}$

2. Annealing buffer

$10 \mathrm{mM}$ Tris $\mathrm{pH} 7.5$

$50 \mathrm{mM} \mathrm{NaCl}$

1 mM EDTA

3. Post irradiation buffer

20 mM Tris- $\mathrm{HCl} \mathrm{pH} 8.0$

$0.1 \%$ SDS

$50 \mathrm{mM} \mathrm{NaCl}$

4. Glycerol loading buffer

$40 \%$ glycerol

10 mM EDTA ( $\mathrm{pH} 8.0$ )

$7.5 \%$ Orange $\mathrm{G}$ dye

5. $20 \%$ Native PAGE 


\author{
$1 \times \mathrm{TBE}$ \\ $20 \%$ acrylamide \\ $0.05 \%$ APS \\ $4 \mu \mathrm{I}$ TEMED
}

\title{
Acknowledgments
}

This work was supported by the National Science Foundation Division of Molecular and Cellular Biosciences [NSF1613534 to M.A.T.] and supported by Baylor University. We thank Gregory Bowman for introducing us to the feasibility of this technique for orientation mapping (Nodelman et al., 2017).

\section{Competing interests}

The authors declare that they have no conflicts of interest with the contents of this article.

\section{References}

1. Graham, B. W., Schauer, G. D., Leuba, S. H. and Trakselis, M. A. (2011). Steric exclusion and wrapping of the excluded DNA strand occurs along discrete external binding paths during MCM helicase unwinding. Nucleic Acids Res 39: 6585-6595.

2. Ishihama, A. (2000). Molecular anatomy of RNA polymerase using protein-conjugated metal probes with nuclease and protease activities. Chem Commun 13: 1091-1094.

3. Kassabov, S. R. and Bartholomew, B. (2004). Site-directed histone-DNA contact mapping for analysis of nucleosome dynamics. Methods Enzymol 375: 193-210.

4. McGeoch, A. T., Trakselis, M. A., Laskey, R. A. and Bell, S. D. (2005). Organization of the archaeal MCM complex on DNA and implications for the helicase mechanism. Nat Struct Mol Biol 12:756-762.

5. Nodelman, I. M., Bleichert, F., Patel, A., Ren, R., Horvath, K. C., Berger, J. M. and Bowman, G. D. (2017). Interdomain communication of the Chd1 chromatin remodeler across the DNA Gyres of the nucleosome. Mol Cell 65(3): 447-459 e446.

6. Owens, J. T., Miyake, R., Murakami, K., Chmura, A. J., Fujita, N., Ishihama, A. and Meares, C. F. (1998). Mapping the $\sigma^{70}$ subunit contact sites on Escherichia coli RNA polymerase with a $\sigma^{70}$ conjugated chemical protease. PNAS 95(11): 6021-6026.

7. Pendergrast, P. S., Chen, Y., Ebright, Y. W. and Ebright, R. H. (1992). Determination of the orientation of a DNA binding motif in a protein-DNA complex by photocrosslinking. Proc Nat/ Acad Sci U S A 89(21): 10287-10291.

8. Perera, H. M. and Trakselis, M. A. (2019). Amidst multiple binding orientations on fork DNA, Saccharolobus MCM helicase proceeds N-first for unwinding. Elife 8: e46096. 